Published in final edited form as:

ACS Chem Biol. 2019 May 17; 14(5): 994-1001. doi:10.1021/acschembio.9b00173.

\title{
Leukemia Cell Cycle Chemical Profiling Identifies the G2-phase Leukemia Specific Inhibitor Leusin-1
}

\author{
Xiaoyu Xia ${ }^{1}$, Yu-Chen Lo ${ }^{1,2}$, Ankur A. Gholkar ${ }^{1}$, Silvia Senese ${ }^{1}$, Joseph Y. Ong ${ }^{1}$, Erick F. \\ Velasquez $^{1}$, Robert Damoiseaux ${ }^{3,4}$, Jorge Z. Torres ${ }^{1,5,6,{ }^{*}}$ \\ ${ }^{1}$ Department of Chemistry and Biochemistry, University of California, Los Angeles, CA 90095. \\ ${ }^{2}$ Program in Bioengineering, University of California, Los Angeles, CA 90095. \\ ${ }^{3}$ Department of Molecular and Medical Pharmacology, University of California, Los Angeles, CA \\ 90095. \\ ${ }^{4}$ California NanoSystems Institute, University of California, Los Angeles, CA 90095. \\ 5Jonsson Comprehensive Cancer Center, University of California, Los Angeles, CA 90095. \\ ${ }^{6}$ Molecular Biology Institute, University of California, Los Angeles, CA 90095.
}

\begin{abstract}
Targeting the leukemia proliferation cycle has been a successful approach to developing antileukemic therapies. However, drug screening efforts to identify novel antileukemic agents have been hampered by the lack of a suitable high-throughput screening platform for suspension cells that does not rely on flow cytometry analyses. We report the development of a novel leukemia cellbased high-throughput chemical screening platform for the discovery of cell cycle phase specific inhibitors that utilizes chemical cell cycle profiling. We have used this approach to analyze the cell cycle response of acute lymphoblastic leukemia CCRF-CEM cells to each of 181,420 drug-like compounds. This approach yielded cell cycle phase specific inhibitors of leukemia cell proliferation. Further analyses of the top G2-phase and M-phase inhibitors identified the leukemia specific inhibitor 1 (Leusin-1). Leusin-1 arrests cells in G2-phase and triggers an apoptotic cell death. Most importantly, Leusin-1 was more active in acute lymphoblastic leukemia cells than other types of leukemias, non-blood cancers, or normal cells and represents a lead molecule for developing antileukemic drugs.
\end{abstract}

\footnotetext{
“Correspondence to: Jorge Z. Torres, UCLA Department of Chemistry and Biochemistry, Los Angeles, CA 90095, Phone: 310-206-2092, torres@chem.ucla.edu. Author Contributions

X.X. and J.Z.T. initiated the project, designed experiments and analyzed results with input from all authors. A.A.G., S.S., J.Y.O., and E.F.V. performed biochemical and cellular assays. Y.C.L. performed CSNAP chemical analyses. R.D. provided compound procurement and compound structure preparation.

ASSOCIATED CONTENT

Supporting Information

The Supporting Information is available free of charge on the ACS Publications website. Supporting Information Figures S1-S3, Tables S1-S3 and Movies S1-S2 described in the main text, including ${ }^{1} \mathrm{H}-\mathrm{NMR}$ spectra for Leusin-1 and compound $\mathbf{1}$ and raw data from CSNAP analyses.

The authors declare no competing financial and non-financial interests.
} 
Acute lymphoblastic leukemia (ALL) originates from single B-or T-lymphocyte progenitors that proliferate and accumulate, resulting in the suppression of normal haematopoesis. 1 The disease is most common in children, but can occur in any age group. ${ }^{1}$ A successful strategy in the treatment of leukemias has been to inhibit leukemia cell proliferation by targeting DNA synthesis, protein synthesis, cell cycle progression, and proliferation-promoting signaling cascades. ${ }^{1}$ Although some antileukemic drugs have been successful at treating specific types of leukemias, most have limited efficacies, mainly due to leukemia cell drug resistance mechanisms, lack of specificity, and toxic side effects. ${ }^{2}{ }^{5}$ Therefore, there is a critical need to identify novel antileukemic drugs with improved chemical properties and efficacy.

Leukemia drug discovery studies have mainly relied on predefined targets identified by genetic abnormalities, differential gene expression or protein abundance between normal and disease states. ${ }^{6}{ }^{7}$ Traditional target-based drug discovery is then used to identify inhibitors to these targets. ${ }^{8}$ However, this process often relies on in vitro activity assays and candidate inhibitors identified using this approach are frequently not cell-permeable, lose their activity or have unintended consequences within the context of the cell, primarily due to off-target effects. ${ }^{9}$ As an alternative approach, chemical genetic drug discovery approaches have utilized cell based assays to identify anticancer agents, which has been highly successful with adherent cancer cells. ${ }^{9}$ However, the difficulty in utilizing suspension cells for highthroughput chemical screens has hampered the progress in identifying novel inhibitors of blood born cancers. Therefore, only a limited number of compounds have been tested for their anticancer activities on human acute myeloid leukemia or lymphoma cells. ${ }^{10},{ }^{11}$ These screens have relied on flow cytometry instruments that are not amenable to high-throughput screening or on endpoint viability assays that lack critical information with regards to the phase of the cell cycle where these compounds are active. ${ }^{10},{ }^{11}$

Here, we report the development and application of a novel leukemia suspension cell-based high-throughput chemical screening approach for leukemia cell cycle profiling and antileukemic drug discovery. This approach identified novel G1/S, G2 and M-phase specific leukemia inhibitors with diverse chemotypes. Importantly, we discovered and characterized the leukemia specific inhibitor 1 (Leusin-1), which specifically arrest leukemia cells during G2-phase and triggers an apoptotic cell death. Leusin-1 showed specificity towards acute lymphoblastic leukemia cells than other types of leukemias, non-bloodborne cancers, or normal cells and represents a lead molecule for antileukemic drug development.

\section{RESULTS AND DISCUSSION}

\section{Discovery of Leukemia Cell Cycle Modulators.}

The limited efficacy, lack of specificity and toxic side effects of current antileukemic drugs ${ }^{2}{ }^{5}$ inspired us to establish an integrated high-throughput suspension cell-based strategy to identify small molecule cell cycle modulators for use in dissecting the mechanisms of leukemia cell proliferation and for the development of novel leukemia therapies (Figure 1A). Briefly, human CCRF-CEM acute lymphoblastic leukemia (ALL) cells were plated into 384 well plates. A diverse compound library (181,420 small drug-like molecules) encompassing broad chemical space was used to place one compound per well at 
a final concentration of $10 \mu \mathrm{M}$. The cells were fixed $16 \mathrm{~h}$ later and stained with the DNAselective stain Vybrant DyeCycle Green, which emits a fluorescent signal when exited at $488 \mathrm{~nm}$ that is proportional to the DNA mass of a cell. Plates were then scanned with an Acumen eX3 fluorescence microplate cytometer using its $488 \mathrm{~nm}$ laser and a cell cycle histogram profile was generated for each compound (Figure 1A). Cell cycle profiles were ranked according to percent G1/S-phase arrest and percent G2/M-phase arrest (Figure 1B, C and Table S1). An example of a compound from each class and its associated cell cycle profile are shown in Figure 1D and E. Compounds that arrested cells in G1/S-phase with >2 standard deviations (SDs) from the DMSO control or in G2/M-phase with $>80 \%$ of the Taxol control were retested in triplicate to confirm their bioactivity. In total $30 \mathrm{G} 1 / \mathrm{S}$-phase and $471 \mathrm{G} 2 / \mathrm{M}$-phase inhibitors were reconfirmed and they accounted for an overall hit rate of $0.28 \%$ (Figure $1 \mathrm{~F}$ and Table S1).

\section{Antileukemic Compound Chemical Analysis.}

The chemical structures and potential targets of the G1/S-phase and G2/M-phase hit antileukemic compounds were analyzed using CSNAP (Chemical Similarity Network Analysis Pulldown), a recently developed computational compound target inference approach based on chemical similarity networks. ${ }^{12}{ }^{15}$ Specifically, CSNAP compared hit compounds to compounds with annotated targets from the ChEMBL database that shared high chemical similarity (see methods for similarity search parameters). The annotated and hit compounds were then ordered into chemical similarity networks where nodes represented compounds and edges represented compound similarities. Using a similarity threshold of 0.6 , the networks were further partitioned into multiple sub-networks that shared similar chemotypes. The chemical similarity networks were used to predict the targets of query compounds based on a nearest-neighbor scoring function, S-score, that ranks the frequency of targets from annotated compounds in the neighborhood of each query. ${ }^{16}$ For our analysis, we generated two chemical similarity networks that corresponded to G1/S and G2/M-phase networks respectively (Figure 2A, B and Table S2). We visualized the number of predicted targets observed in each cell cycle phase using a heatmap where the color intensity was scaled and normalized according to the S-score of each target (Figure 2C, D and Table S2).

Furthermore, we identified the most abundant targets by determining the accumulated Sscore ( $\Sigma$ S-Score) across both G1/S and G2/M-phase compounds (Figure 2C, D and Table $\mathrm{S} 2$ ). This analysis grouped the $30 \mathrm{G} 1 / \mathrm{S}$-phase compounds into 25 chemotype clusters and the 471 G2/M-phase compounds into 96 chemotype clusters (Figure 2A, B and Table S2). The top predicted targets for G1/S-phase inhibitors were proteins involved in signaling pathways that promote cell growth and proliferation (Figure 2C and Table S2). The top predicted targets for G2/M-phase inhibitors were tubulin isoforms (Figure 2D and Table S2). Because of our interest in cell division, we sought to analyze the G2/M-phase network further. However, due to the overabundance of screening campaigns aimed at discovering microtubule-targeting agents, we eliminated all chemotype clusters that were predicted to be targeting microtubules $(\alpha / \beta$-tubulin) from further consideration. This resulted in 4 remaining chemotype clusters and 45 orphan compounds that did not share significant chemical similarity to other compounds in the ChEMBL database (for example see boxed compounds in Figure 2B). Two compounds from each novel chemotype cluster and the 45 orphan 
compounds (total of 53 compounds) were selected, re-synthesized and subjected to further evaluation in secondary assays (Table S3).

\section{G2/M-phase Antileukemic Compound Potency.}

To assess the potential of the 53 selected compounds as antileukemic agents, we tested them for their ability to inhibit CCRF-CEM ALL cell viability. For viability assays, cells were treated with each compound for $72 \mathrm{~h}$ and their viability was measured using the CellTiterGlo luminescent cell viability assay (Promega), which measures total ATP levels (indicative of metabolically active cells) using a luminometer at a wavelength of $560 \mathrm{~nm}$ (Figure 3A and B). These assays were carried out in triplicate with a twenty-step series of two-fold dilutions (50 $\mu \mathrm{M}$ to $95.37 \mathrm{pM}$ ) for each compound and their cell viability $\mathrm{IC}_{50}$ (half maximal inhibitory concentration) were derived (Figure 3B and Table S3). This analysis revealed that most compounds (51) had a cell viability $\mathrm{IC}_{50}<5 \mu \mathrm{M}$ (Figure 3B and Table S3).

\section{Multiparametric Phenotypic Analysis of Leukemia G2/M-phase Inhibitors.}

To further explore the mechanism of action of G2/M-phase inhibitors, we analyzed the cellular response of cells to these inhibitors by immunofluorescence (IF) microscopy. Due to the difficulty in performing IF microscopy on CCRF-CEM cells, HeLa cells were treated with each of the 53 compounds at a concentration corresponding to their CCRF-CEM cell viability $\mathrm{IC}_{90}$ for $16 \mathrm{~h}$. Cells were then fixed, permeabilized, co-stained for DNA and $\mathrm{a}$ tubulin, and imaged at $63 \mathrm{X}$ magnification. Surprisingly, 51 compounds arrested cells with depolymerized microtubules, indicating that they represented novel chemotypes that were targeting microtubules (Table S3). Consistently, staining of the cells with a FITC fluorescently labeled antibody that recognizes the mitotic marker phosphorylated histone $\mathrm{H} 3$ $\left(\mathrm{p}-\mathrm{H} 3{ }^{17},{ }^{18}\right)$, indicated that 51 compounds had an increased percentage of cells arrested in mitosis (\% mitotic cells $=$ number of $\mathrm{p}-\mathrm{H} 3$ positive cells/total number of cells that stained positive with the Hoechst 33342 DNA dye) compared to controls (Figure 3C and D). However, N-(5-methyl-4,5,6,7-tetrahydrothiazolo[5,4-c]pyridin-2-yl)-5nitrobenzo[b]thiophene-2-carboxamide hydrochloride (Leukemia specific inhibitor 1; Leusin-1) and 4-(((3,5-dimethoxybenzyl)thio)methyl)thiazol-2-amine (compound $\mathbf{1})$ induced a decrease in the percentage of mitotic cells (Figures 3D and E, and Table S3). In HeLa cells, Leusin-1 and compound $\mathbf{1}$ had no effect on the interphase microtubule cytoskeletal network or on the mitotic microtubule spindle, even at the high dose of $137 \mu \mathrm{M}$ for Leusin-1 or $180 \mu \mathrm{M}$ for compound 1 (Figures $4 \mathrm{~A}$ and S1). Further testing of Leusin-1 and compound 1, using an in vitro microtubule polymerization assay, showed that they had no effect on microtubule polymerization, similar to the DMSO control (Figure 4B). In contrast, Taxol increased the rate of microtubule polymerization, whereas colchicine and nocodazole abolished microtubule polymerization (Figure 4B). However, compound $\mathbf{1}$ proved to be an unstable compound and lost activity over time in suspension. Therefore, we selected Leusin-1 for further analysis based on its novel chemotype, its stable biochemical properties and its inhibition of leukemia cell division through a G2-phase arresting and nonmicrotubule targeting mechanism. To further verify that Leusin-1 was a G2-phase inhibitor we treated CCRF-CEM cells with thymidine (G1/S-phase arrest), Taxol (M-phase arrest), RO-3306 (G2-phase arrest ${ }^{19}$ ) or Leusin-1 and analyzed the status of cell cycle biochemical markers by immunoblot analysis. Consistently, Taxol, RO-3306 and Leusin-1 arrested cells 
with lower levels of Cyclin E (levels peak at G1/S-phase) and increased levels of Cyclin B (levels peak at G2/M-phase) (Figure 4C). However, unlike Taxol, RO-3306 and Leusin-1 also arrested cells with lower levels of p-H3 (present only in M-phase) and increased levels of Cyclin A (levels peak in G2-phase) (Figure 4C). Additionally, flow-cytometry analyses of CCRF-CEM cells treated with either DMSO, Nocodazole, or Leusin-1 showed that Luesin-1 was arresting cells in G2/M-phase (Figure S2). Together these data indicated that Leusin-1 was arresting CCRF-CEM cells specifically in G2-phase through a non-microtubule targeting mechanism.

\section{Leusin-1 Arrests Cells in G2-phase and Triggers an Apoptotic Cell Death.}

To determine the consequences of arresting cells in G2-phase with Leusin-1, we analyzed the biochemical response of cells treated with Leusin-1. CCRF-CEM cells were treated with Leusin-1, cisplatin (G2-phase inhibitor) or Taxol (M-phase inhibitor) and protein extracts were prepared after $24 \mathrm{~h}$. Consistent with our previous data, immunoblot analyses of protein samples using antibodies directed against $\mathrm{p}-\mathrm{H} 3$ (phosphorylated in mitosis) indicated that Leusin- 1 and cisplatin arrested cells with limited p-H3 staining, indicative of a G2-phase arrest, whereas Taxol arrested cells with increased p-H3 levels, indicative of a M-phase arrest (Figure 5A). Interestingly, Leusin-1 induced the cleavage of caspase-3, indicative of apoptotic pathway activation (Figure 5A). These data indicated that Leusin-1 arrested cells prior to mitosis and triggered an apoptotic cell death. To further test this, CCRF-CEM cells were treated with DMSO, Leusin-1 or Taxol for $48 \mathrm{~h}$ and the extent of caspase-3/7 activation was measured using the Caspase-Glo luminescent caspase activity assay. ${ }^{20}$ This assay revealed that Leusin-1 was indeed inducing an apoptotic cell death similar to Taxol treatment (Figure 5B). Next, we performed live-cell time-lapse microscopy on CCRF-CEM cells treated with DMSO or Leusin-1. DMSO treated cells were able to divide normally, whereas Leusin-1 treated cells never divided and eventually underwent apoptosis (Figure 5C and Movies S1 and S2). Together these data indicated that Leusin-1 was arresting cells in G2-phase and triggering an apoptotic cell death.

\section{Leusin-1 is an ALL Specific Inhibitor.}

To determine whether Leusin-1 was active against a broad array of cancers or was specific for leukemias, we treated a diverse panel of cancer cell lines and normal cell lines with Leusin-1 for $72 \mathrm{~h}$. These included cervical adenocarcinoma (HeLa), breast adenocarcinoma (MCF-7), melanoma (M233), osteosarcoma (U-2 OS), lung adenocarcinoma (NCI-H560), acute lymphoblastic leukemia (CCRF-CEM), retinal pigment epithelial cells (hTERT-RPE), Lymphoma (Jeko-1), and colorectal carcinoma (HCT 116). The cell viability $\mathrm{IC}_{50}$ was then quantified and compared to the DMSO control (Figure 6A). Interestingly, Leusin-1 showed specificity for CCRF-CEM cells compared to all other adherent types of cancers (CCRFCEM cell viability $\mathrm{IC}_{50}$ for Leusin- $1=2.64 \mu \mathrm{M}$ compared to $4-50$-fold higher for all other cell lines) (Figure 6A). To determine if Leusin-1 was active against all leukemias (nonadherent cells) or only a subset of leukemias, we analyzed the efficacy of Leusin-1 on a panel of leukemia cell lines. These included acute lymphoblastic leukemia (ALL; CCRFCEM and TOM1), acute myeloid leukemia (AML; HL-60 and THP1), and chronic myeloid leukemia (CML; K562 and KCL22) cell lines. Surprisingly, ALL cell lines were the most sensitive to Leusin-1 (CCRF-CEM IC $\mathrm{I0}_{5}=2.66 \mu \mathrm{M}$ and $\mathrm{TOM} 1 \mathrm{IC}_{50}=0.877 \mu \mathrm{M}$, compared to 
5-30 $\mu \mathrm{M}$ for all other leukemia cell lines) (Figure 6B). These results indicated that Leusin-1 was most potent against acute lymphoblastic leukemias.

\section{Leusin-1 Inhibits ALL Colony Formation.}

Next, we assessed the ability of Leusin-1 to inhibit CCRF-CEM colony formation using two separate clonogenic assays (Figure 6C, D, and E). First, an agar-based colony formation assay was performed in the presence of DMSO, Taxol or Leusin-1 and colony formation was visualized with crystal violet stain and the total number of colonies were quantified. Interestingly, Leusin-1 was able to inhibit colony formation similar to Taxol (Figure 6C and D). Next, we analyzed the effect of Leusin-1 on colony formation using the CytoSelect ${ }^{\mathrm{TM}}$ Cell Transformation Assay kit (Cell Biolabs, Inc.), which measures the total number of viable cells in agar solutions. Consistently, Leusin-1 inhibited colony formation similar to Taxol (Figure 6E). Together these data indicated that Leusin-1 was inhibiting CCRF-CEM colony formation.

\section{Conclusions.}

Cell cycle checkpoints ensure that the progression of the cell cycle from one phase to another is regulated with precision and occurs with high fidelity. ${ }^{21}$ Dysregulation of the G1/S, S, G2, and M-phase cell cycle checkpoints can lead to abnormal cell proliferation and carcinogenesis. ${ }^{21}$ A strategy for developing leukemia therapeutics has been to develop inhibitors that perturbed the cell cycle and lead to a cell cycle arrest and subsequent apoptotic cell death. ${ }^{22},{ }^{23}$ However, the difficulty of analyzing the cell cycle response of suspension cells to chemical treatments has hampered leukemia cell-based high-throughput drug discovery efforts. Although a limited number of compounds have been screened in acute myeloid leukemia and lymphoma cells, these studies have relied on flow cytometry that is not easily amenable to high-throughput screening or on endpoint assays that lack critical information on the cell cycle phase where these compounds are active. ${ }^{10},{ }^{11}$ To address this, we engineered our high-throughput cell cycle profiling chemical screening platform to be compatible with suspension leukemia cells and screened 181,420 drug-like compounds in leukemia CCRF-CEM cells. ${ }^{14}$ This approached yielded novel G1/S, G2 and M-phase specific inhibitors of acute lymphoblastic leukemia cell proliferation, which included novel chemotypes targeting each phase. Although we did not pursue the M-phase microtubule-targeting agents, it is important to note that microtubule-targeting agents continue to be used broadly for the treatment of cancer and the new chemotypes discovered in this study could be used to develop more effective microtubule-targeting therapeutics. ${ }^{24}$

Our data indicates that Luesin-1 is an exciting molecule to pursue for developing new acute lymphoblastic leukemia therapies. First, Leusin-1 potently arrests the leukemia cell cycle in G2-phase and triggers an apoptotic cell death, thereby inhibiting leukemia cell proliferation. Second, Leusin-1 is not a microtubule-targeting agent, which are often associated with numerous side-effects like neurotoxicities and neutropenia. ${ }^{24}$ Third, in comparison to other leukemia therapeutics, either in the clinic or FDA approved for the treatment of leukemias like vinblastine, Leusin-1 appears to have a greater specificity for leukemia cells (ALL in particular) compared to other cancer cell types and normal cells. This Leusin-1 specificity for acute lymphoblastic leukemias represents a vantage point for the development of therapeutics with a more favorable therapeutic window. Future studies related to defining the 
Leusin-1 mechanism of action should help to elucidate the underlying sensitivity of acute lymphoblastic leukemias to Leusin-1.

\section{METHODS \\ Compounds.}

Leusin-1 and compound $\mathbf{1}$ were purchased from Life Chemicals Inc. with greater than $95 \%$ purity. For 1H-NMR of Leusin-1 and compound 1, see Figure S3.

\section{Cell Culture.}

All human cell lines, with the exception of M233, were purchased from ATCC, were verified identity by short-tandem repeat profiling, were passaged for less than 6 months following receipt and were maintained in $5 \% \mathrm{CO}_{2}$ at $37{ }^{\circ} \mathrm{C}$ in RPMI1640 medium (CCRF-CEM, Jeko-1, NCI-H560, TOM1, KCL22, THP1), DMEM/F12 (HeLa, hTERT-RPE), McCoy's 5A (U-2 OS, HCT 166), IMDM (K562, HL-60) or EMEM (MCF-7) with 10\% FBS, 2 mM Lglutamine and antibiotics. M233 was established from a patient biopsy under UCLA IRB approval \#02-08-067, as described previously. ${ }^{25} \mathrm{M} 233$ was genotyped using the Oncomap3 platform for 33 genes, Affymetrix Gene Chip for SNP and IonTorrent for next-generation sequencing, and passaged for less than 6 months following verification and maintained in RPMI1640 with $10 \% \mathrm{FBS}$ and antibiotics in $5 \% \mathrm{CO}_{2}$ at $37^{\circ} \mathrm{C}$. All medias were purchased from ThermoFisher.

\section{High-throughput Screening.}

Screening conditions were as described previously ${ }^{14}$, with the following modifications. CCRF-CEM cells were plated in 384-well plates (1,000 cells/well) and treated with $10 \mu \mathrm{M}$ drugs for $16 \mathrm{~h}$. Cells were fixed and stained with $2.5 \mu \mathrm{M}$ Vybrant DyeCycle Green (Invitrogen) for $3 \mathrm{~h}$ at room temperature and plates were scanned with an Acumen eX3 (TTP Labtech) fluorescence cytometer using its $488 \mathrm{~nm}$ laser and a cell cycle histogram profile was generated for each well. For the G2/M-phase secondary screen, $16 \mathrm{~h}$ post drug-addition HeLa cells were fixed with $4 \%$ paraformaldehyde, permeabilized with $0.1 \%$ Triton X-100/PBS and stained with Alexa Fluor 488 phospho-histone-H3 (Ser10, Cell Signaling) and $0.25 \mu \mathrm{g} / \mathrm{ml}$ Hoechst 33342 for $1 \mathrm{~h}$. Plates were washed twice with PBS using a microplate washer (BioTek), then imaged with an ImageXpress Micro (Molecular Devices) high-content fluorescence microscope. Data analysis was performed using the CDD (Collaborative Drug Discovery) software and outputs were exported to Excel.

\section{Compound Potency.}

For cell viability $\mathrm{IC}_{50}$, CCRF-CEM cells were treated with a twenty-step series of two-fold dilutions $(50 \mu \mathrm{M}$ to $95.37 \mathrm{pM})$. Cell viability $\mathrm{IC}_{50}$ was determined using the CellTiter-Glo Assay (Promega), which measures total ATP levels. Plates were read with a Tecan M1000 micro-plate reader at $540 \mathrm{~nm}$ and $\mathrm{CDD}$ software was used for generating $\mathrm{IC}_{50}$ and $\mathrm{IC}_{90}$ values. 


\section{Immunofluorescence and Time-lapse Microscopy.}

Immunofluorescence microscopy was carried out as described previously ${ }^{26}$ using $\mathrm{HeLa}$ cells, except that images were captured with a Leica DMI6000 microscope (Leica Microsystems) and deconvolved with Leica deconvolution software. Time-lapse microscopy was performed as described previously. ${ }^{17}$ Briefly, CCRF-CEM cells were treated with DMSO or Leusin-1 $(5 \mu \mathrm{M})$ and ten Z-stack images ( $0.9 \mu \mathrm{m}$ steps) were captured at 15 minute intervals. Images were deconvolved and converted to AVI movie files.

\section{Apoptosis Assays.}

CCRF-CEM cells were treated with the indicated drugs for $48 \mathrm{~h}$ and the Caspase-Glo luminescent caspase activity assay (Promega) was used to measure the activity of effector caspases, as a read-out of apoptosis. Plates were scanned with a luminometer at a wavelength of $520 \mathrm{~nm}$ and the apoptotic index (total caspase activity/total number of cells) per well was measured. Quantitation is in relative light units (RLU) compared to DMSO control.

\section{Leukemia Clonogenic Assays.}

5,000 CCRF-CEM cells/well were grown in 6-well plates with semisolid RPMI1640 medium containing $10 \%$ FBS, $0.45 \%$ agarose, and drug (1\% DMSO, $2 \mu$ M Leusin- 1 or 50 $\mathrm{nM}$ Taxol). A layer of $500 \mu \mathrm{L}$ of medium containing the corresponding drug was added on top and plates were incubated in $5 \% \mathrm{CO}_{2}$ at $37{ }^{\circ} \mathrm{C}$ for 3 weeks. Fresh medium was replenished twice a week. Colonies ( $>30$ cells) were scored and visualized after the addition of $0.005 \%$ crystal violet overnight.

\section{Leukemia Cell Transformation Assay.}

CytoSelect ${ }^{\mathrm{TM}}$ 96-Well Cell Transformation Assay kit (Cell Biolabs, Inc.) was used for assessing soft agar colony formation following the manufacturer's instructions for seven days. Fluorescent signals from DMSO, Leusin-1 $(2 \mu \mathrm{M})$, or Taxol $(50 \mathrm{nM})$ treated cells were normalized after subtracting the value from the no cell blank, and the mean values of the samples were plotted as relative light units (RLU).

\section{CSNAP Chemical Analysis.}

CSNAP was used to predict the targets of G1/S-phase and G2/M-phase inhibitors as described previously ${ }^{12}$. Briefly, compounds were queried in the annotated ChEMBL database version 18 using the following search parameters: Tanimoto cutoff $=0.75, \mathrm{z}$-score cutoff $=2.5$. The ChEMBL target annotations were retrieved from the database based on the following criteria: confidence score $=4$, assay-type=binding. Finally, chemical similarity networks and ligand-target interaction fingerprints (LTIFs) analyses were analyzed using Cytoscape and the R statistical package respectively.

\section{In Vitro Tubulin Polymerization Assays.}

Tubulin polymerization reactions were carried out according to the manufacturer (Cytoskeleton, BK011P) in the presence of DMSO, $3 \mu \mathrm{M}$ of either Leusin-1, compound $\mathbf{1}$, 
Taxol or colchicine. Polymerization was monitored with a Tecan M1000 micro-plate reader at $420 \mathrm{~nm}$ for 120 minutes at $37{ }^{\circ} \mathrm{C}$.

\section{Antibodies.}

The following antibodies were used in this study. Phospho-histone-H3 Alexa Fluor 488 (Ser10) (Cell Signaling cat\# 3465); a-tubulin (Serotec cat\#MCAP77G); Caspase-3 (Cell Signaling Technology cat\#9665); p-H3 (Cell Signaling cat\#9701); Cyclin A, Cyclin B, Cyclin E (Santa Cruz Biotechnology cat\#sc-751, sc-245, sc-481); Gapdh (GeneTex cat\# GTX627408). FITC and Cy3 conjugated secondary antibodies were from Jackson Immuno Research.

\section{Software.}

The CSNAP program is available as a web server http://services.mbi.ucla.edu/CSNAP/.

\section{Statistical Analysis.}

The quality of the screen was assessed by calculating the $\left(Z^{\prime}\right.$ factor $\left.=1-3\left(\sigma_{\mathrm{p}}+\sigma_{\mathrm{n}}\right)\left(\left|\mu_{p}-\mu_{n}\right|\right)\right)$, which takes into account the dynamic range of the assay and variance of the data. ${ }^{27}$ The screen performed with an average plate $\mathrm{Z}$ ' factor of $0.48 \pm 0.06$, close to the optimal performance range of $0.5-1 .{ }^{27}$

\section{Supplementary Material}

Refer to Web version on PubMed Central for supplementary material.

\section{ACKNOWLEDGEMENTS}

Work performed in the Molecular Screening Shared Resource was supported by the National Cancer Institute of the National Institutes of Health under award number P30CA016042. J.Z.T. was supported by a Jonsson Cancer Center Foundation seed grant, the V Foundation for Cancer Research V Scholar Award, the Research Corporation for Science Advancement Cottrell Scholar Award, and the University of California Cancer Research Coordinating Committee Funds. J.Y.O. was supported by a Ruth L. Kirschstein National Research Service Award GM007185. E.F.V. was supported by a UCLA Molecular Biology Institute Whitcome Fellowship.

\section{REFERENCES}

1. Pui CH, and Jeha S. (2007) New therapeutic strategies for the treatment of acute lymphoblastic leukaemia, Nat Rev Drug Discov 6, 149-165. [PubMed: 17268486]

2. Vagace JM, de la Maya MD, Caceres-Marzal C, Gonzalez de Murillo S, and Gervasini G. (2012) Central nervous system chemotoxicity during treatment of pediatric acute lymphoblastic leukemia/ lymphoma, Crit Rev Oncol Hematol

3. Shaffer BC, Gillet JP, Patel C, Baer MR, Bates SE, and Gottesman MM (2012) Drug resistance: Still a daunting challenge to the successful treatment of AML, Drug Resist Updat 15, 62-69. [PubMed: 22409994]

4. Woessner DW, Lim CS, and Deininger MW (2011) Development of an effective therapy for chronic myelogenous leukemia, Cancer J 17, 477-486. [PubMed: 22157291]

5. Wierda WG, Chiorazzi N, Dearden C, Brown JR, Montserrat E, Shpall E, Stilgenbauer S, Muneer S, and Grever M. (2010) Chronic lymphocytic leukemia: new concepts for future therapy, Clin Lymphoma Myeloma Leuk 10, 369-378. [PubMed: 21030350] 
6. Iacobucci I, Papayannidis C, Lonetti A, Ferrari A, Baccarani M, and Martinelli G. (2012) Cytogenetic and molecular predictors of outcome in acute lymphocytic leukemia: recent developments, Curr Hematol Malig Rep 7, 133-143. [PubMed: 22528731]

7. Kristensen VN, Lingjaerde OC, Russnes HG, Vollan HK, Frigessi A, and Borresen-Dale AL (2014) Principles and methods of integrative genomic analyses in cancer, Nat Rev Cancer 14, 299-313. [PubMed: 24759209]

8. Martell RE, Brooks DG, Wang Y, and Wilcoxen K. (2013) Discovery of novel drugs for promising targets, Clin Ther 35, 1271-1281. [PubMed: 24054704]

9. Cong F, Cheung AK, and Huang SM (2012) Chemical genetics-based target identification in drug discovery, Annu Rev Pharmacol Toxicol 52, 57-78. [PubMed: 21819237]

10. McDermott SP, Eppert K, Notta F, Isaac M, Datti A, Al-Awar R, Wrana J, Minden MD, and Dick JE (2012) A small molecule screening strategy with validation on human leukemia stem cells uncovers the therapeutic efficacy of kinetin riboside, Blood 119, 1200-1207. [PubMed: 22160482]

11. Gasparetto M, Gentry T, Sebti S, O’Bryan E, Nimmanapalli R, Blaskovich MA, Bhalla K, Rizzieri D, Haaland P, Dunne J, and Smith C. (2004) Identification of compounds that enhance the antilymphoma activity of rituximab using flow cytometric high-content screening, J Immunol Methods 292, 59-71. [PubMed: 15350512]

12. Lo YC, Senese S, Li CM, Hu Q, Huang Y, Damoiseaux R, and Torres JZ (2015) Large-scale chemical similarity networks for target profiling of compounds identified in cell-based chemical screens, PLoS Comput Biol 11, e1004153.

13. Lo YC, Senese S, Damoiseaux R, and Torres JZ (2016) 3D Chemical Similarity Networks for Structure-Based Target Prediction and Scaffold Hopping, ACS Chem Biol 11, 2244-2253. [PubMed: 27285961]

14. Senese S, Lo YC, Huang D, Zangle TA, Gholkar AA, Robert L, Homet B, Ribas A, Summers MK, Teitell MA, Damoiseaux R, and Torres JZ (2014) Chemical dissection of the cell cycle: probes for cell biology and anti-cancer drug development, Cell Death Dis 5, e1462.

15. Lo YC, Senese S, France B, Gholkar AA, Damoiseaux R, and Torres JZ (2017) Computational Cell Cycle Profiling of Cancer Cells for Prioritizing FDA-Approved Drugs with Repurposing Potential, Sci Rep 7, 11261. [PubMed: 28900159]

16. Lo YC, Rensi SE, Torng W, and Altman RB (2018) Machine learning in chemoinformatics and drug discovery, Drug Discov Today 23, 1538-1546. [PubMed: 29750902]

17. Torres JZ, Summers MK, Peterson D, Brauer MJ, Lee J, Senese S, Gholkar AA, Lo YC, Lei X, Jung K, Anderson DC, Davis DP, Belmont L, and Jackson PK (2011) The STARD9/Kif16a Kinesin Associates with Mitotic Microtubules and Regulates Spindle Pole Assembly, Cell 147, 1309-1323. [PubMed: 22153075]

18. Hendzel MJ, Wei Y, Mancini MA, Van Hooser A, Ranalli T, Brinkley BR, Bazett-Jones DP, and Allis CD (1997) Mitosis-specific phosphorylation of histone H3 initiates primarily within pericentromeric heterochromatin during G2 and spreads in an ordered fashion coincident with mitotic chromosome condensation, Chromosoma 106, 348-360. [PubMed: 9362543]

19. Vassilev LT, Tovar C, Chen S, Knezevic D, Zhao X, Sun H, Heimbrook DC, and Chen L. (2006) Selective small-molecule inhibitor reveals critical mitotic functions of human CDK1, Proc Natl Acad Sci U S A 103, 10660-10665. [PubMed: 16818887]

20. Chowdhury I, Tharakan B, and Bhat GK (2008) Caspases-an update, Comp Biochem Physiol B Biochem Mol Biol 151, 10-27. [PubMed: 18602321]

21. Williams GH, and Stoeber K. (2012) The cell cycle and cancer, J Pathol 226, 352-364. [PubMed: 21990031]

22. Halicka HD, Seiter K, Feldman EJ, Traganos F, Mittelman A, Ahmed T, and Darzynkiewicz Z. (1997) Cell cycle specificity of apoptosis during treatment of leukaemias, Apoptosis 2, 25-39. [PubMed: 14646562]

23. Ghelli Luserna di Rora A, Iacobucci I, and Martinelli G. (2017) The cell cycle checkpoint inhibitors in the treatment of leukemias, J Hematol Oncol 10, 77. [PubMed: 28356161]

24. Arnst KE, Banerjee S, Chen H, Deng S, Hwang DJ, Li W, and Miller DD (2019) Current advances of tubulin inhibitors as dual acting small molecules for cancer therapy, Med Res Rev 
25. Sondergaard JN, Nazarian R, Wang Q, Guo D, Hsueh T, Mok S, Sazegar H, MacConaill LE, Barretina JG, Kehoe SM, Attar N, von Euw E, Zuckerman JE, Chmielowski B, Comin-Anduix B, Koya RC, Mischel PS, Lo RS, and Ribas A. (2010) Differential sensitivity of melanoma cell lines with BRAFV600E mutation to the specific Raf inhibitor PLX4032, J Transl Med 8, 39. [PubMed: 20406486]

26. Torres JZ, Ban KH, and Jackson PK (2010) A Specific Form of Phospho Protein Phosphatase 2 Regulates Anaphase-promoting Complex/Cyclosome Association with Spindle Poles, Mol Biol Cell 21, 897-904. [PubMed: 20089842]

27. Zhang JH, Chung TD, and Oldenburg KR (1999) A Simple Statistical Parameter for Use in Evaluation and Validation of High Throughput Screening Assays, J Biomol Screen 4, 67-73. [PubMed: 10838414] 
A

Leukemia

CCRF-CEM cells

181,420

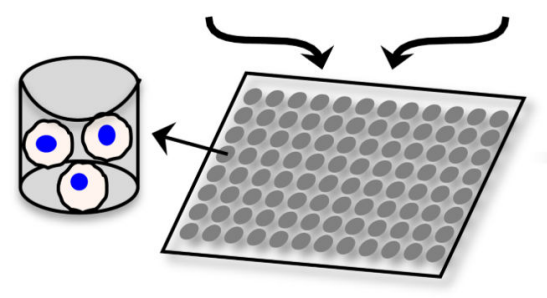

B

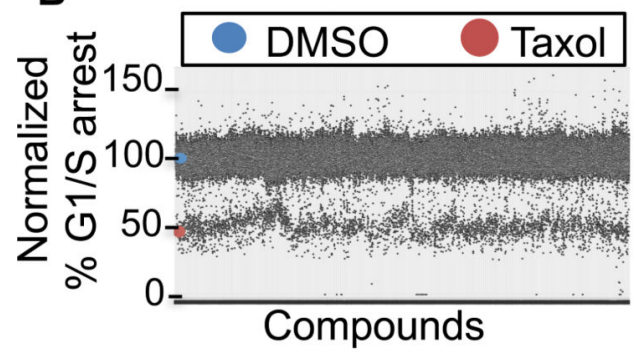

D

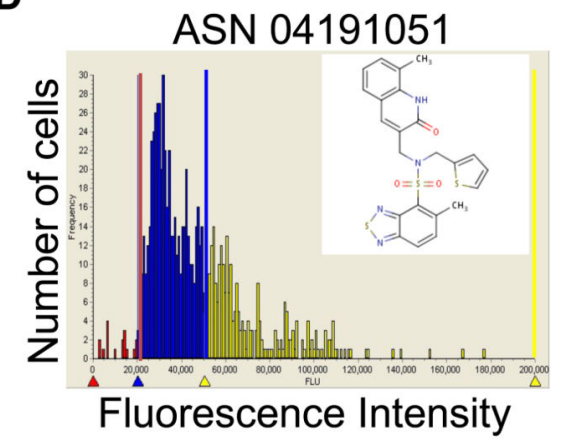

Cell cycle profile/well

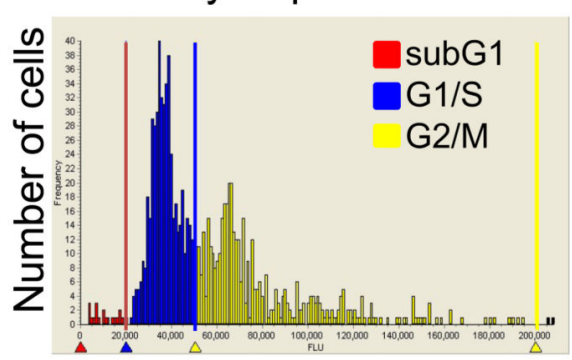

Fluorescence intensity

C

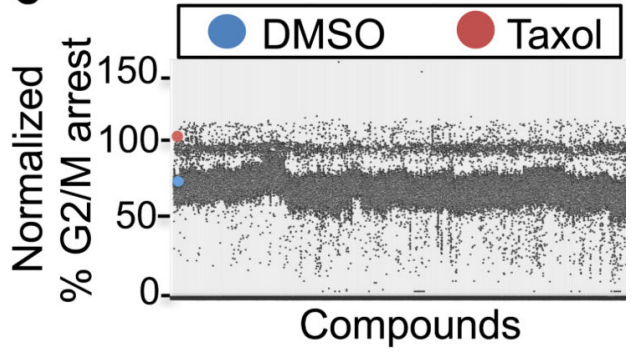

E

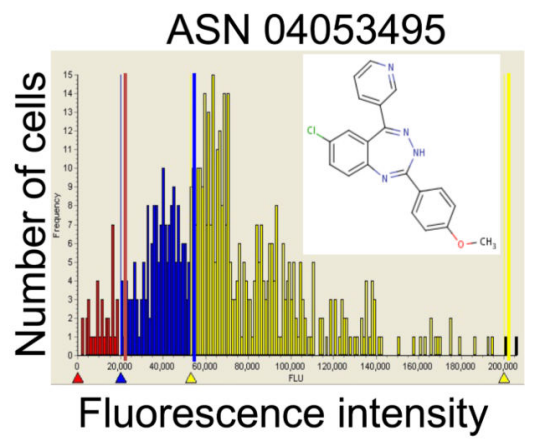

F

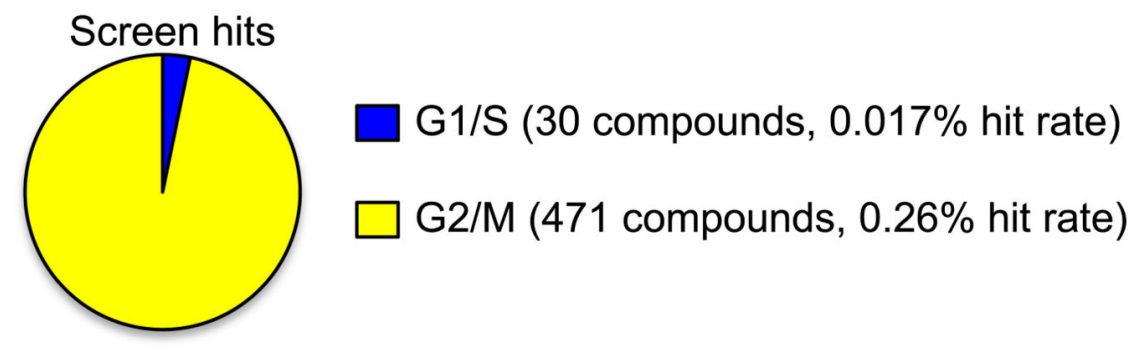

Figure 1.

Overview of the leukemia suspension cell-based high-throughput cell cycle profiling chemical screening approach and summary of screen results. (A) Summary of screening approach where leukemia CCRF-CEM cells were treated with each of 181,420 compounds (at $10 \mu \mathrm{M}$ ) for $16 \mathrm{~h}$. Cells were then fixed and stained with Vybrant DyeCycle green and a cytometer was used to generate a cell cycle profile for each compound based on the fluorescence intensity that is proportional to a cell's DNA mass. Fluorescence intensity is in arbitrary units (X-axis) and the total number of cells is on the y-axis. (B,C) Graphs show the 
percent G1/S-phase and G2/M-phase arrest (y-axis) for each of the 181,420 compounds ( $\mathrm{x}$ axis). The cutoffs for G1/S-phase inhibitors was set at $>2$ SDs from the average of the DMSO controls. The cutoff for G2/M-Phase inhibitors was set at $>80 \%$ of the Taxol positive control average. (D,E) An example of compounds arresting the cell cycle in G1/S-phase and G2/M-phase and their cell cycle profiles. (F) Summary of screen hits. In total $30 \mathrm{G} 1 / \mathrm{S}$-phase inhibitors and $471 \mathrm{G} 2 / \mathrm{M}$-phase inhibitors were identified with an overall $0.28 \%$ hit rate. (BF) See also Table S1. 
A G1/S B
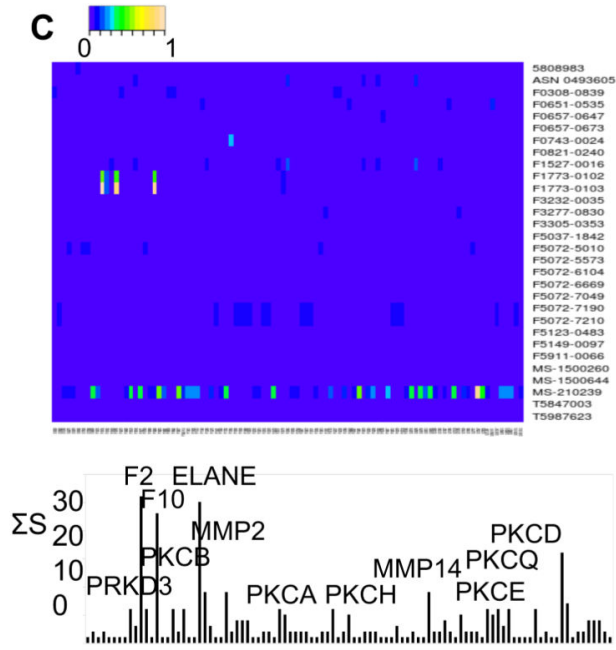
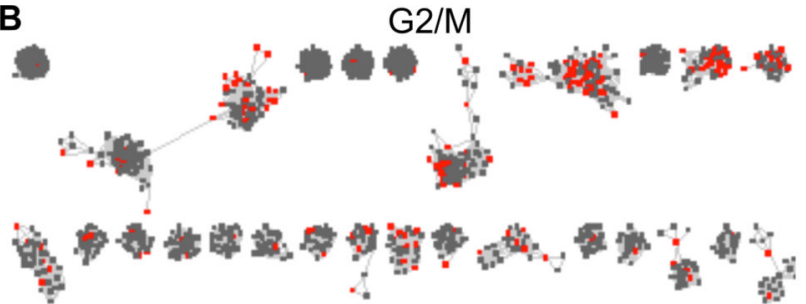

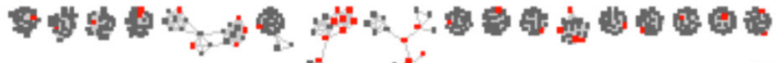

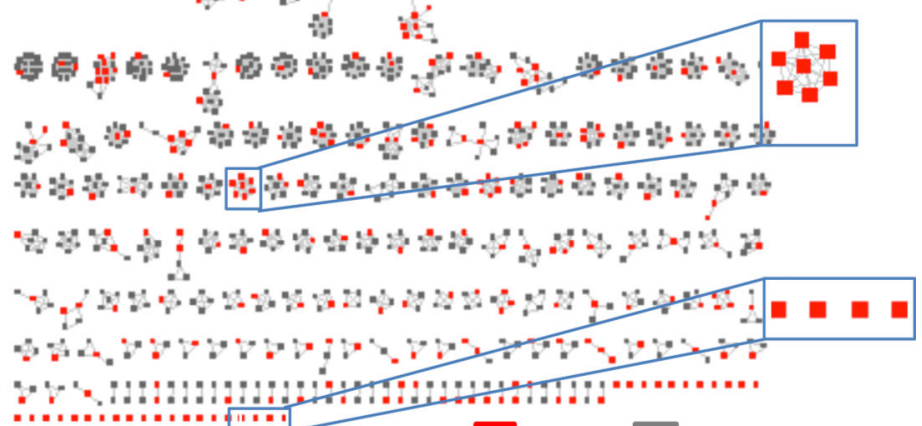

D
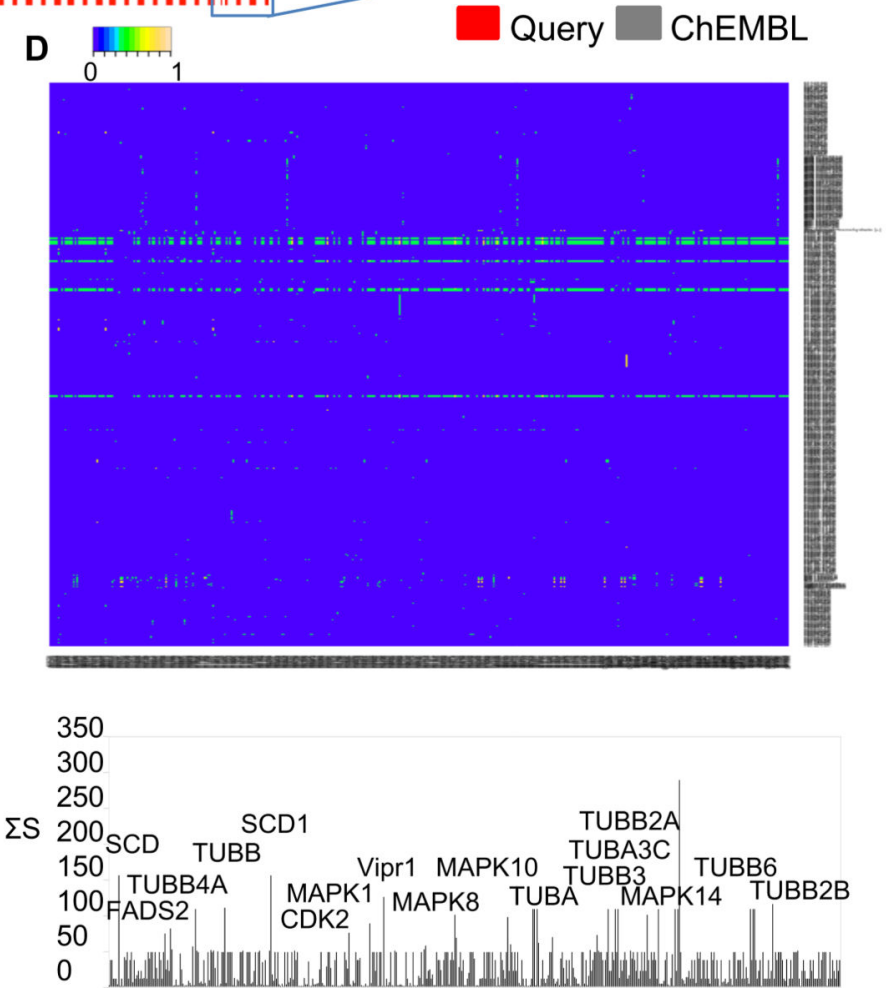

Figure 2.

Chemical analysis of leukemia G1/S-phase and G2/M-phase specific inhibitors. (A) CSNAP chemical similarity network of G1/S-phase inhibitors. Note that these compounds organized into 25 chemotypic clusters and 2 compounds remained orphaned. Query compounds are in red and ChEMBL compounds are in grey. (B) CSNAP Chemical similarity network of G2/M-phase inhibitors. These compounds organized into 96 chemotypic clusters and 45 compounds remained orphaned. Query compounds are in red and ChEMBL compounds are in grey. (C-D) Heatmap summaries of CSNAP S-scores, scaled from 0 to 1 . The cumulative 
S-score ( $\Sigma S$-Score) of each assigned target in the target spectrum and the major predicted targets/off-targets are indicated. (A-D) See also Table S2. 

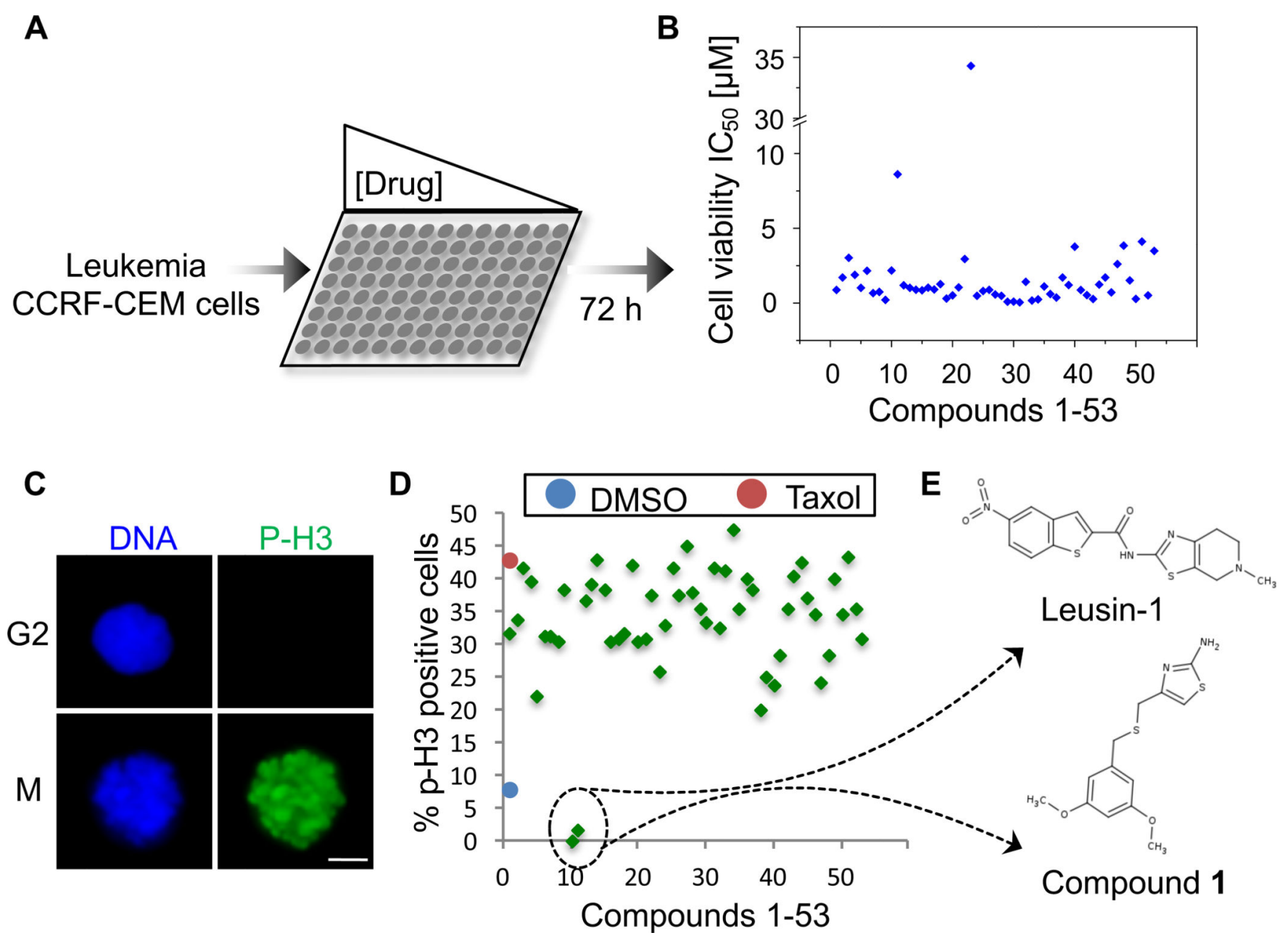

Figure 3.

Leukemia G2/M-phase inhibitor potency. (A) CCRF-CEM cells were treated with increasing concentrations (95.37 pM to $50 \mu \mathrm{M}$ ) of each compound for $72 \mathrm{~h}$ and the cell viability was assessed using the CellTiter-Glo assay. (B) Summary graph showing the cell viability IC $_{50}$ of each compound ( $\mathrm{x}$-axis) in $\mu \mathrm{M}$ scale (y-axis). Note that 53 compounds have a cell viability $\mathrm{IC}_{50}$ below $5 \mu \mathrm{M}$. See also Table S3. (C) Assay to measure percentage of mitotic cells. Cells were stained with Hoechst 33342 DNA dye (to measure total cells) and Alexa Fluor 488-pH3 antibodies (to measure number of mitotic cells). Scale bar indicates $5 \mu \mathrm{m}$. (D) Summary of the percentage of cells in mitosis (y-axis) for each of the 53 compounds ( $\mathrm{x}$ axis). (E) Chemical structures of Leusin-1 and compound 1 G2 phase inhibitors. 
A

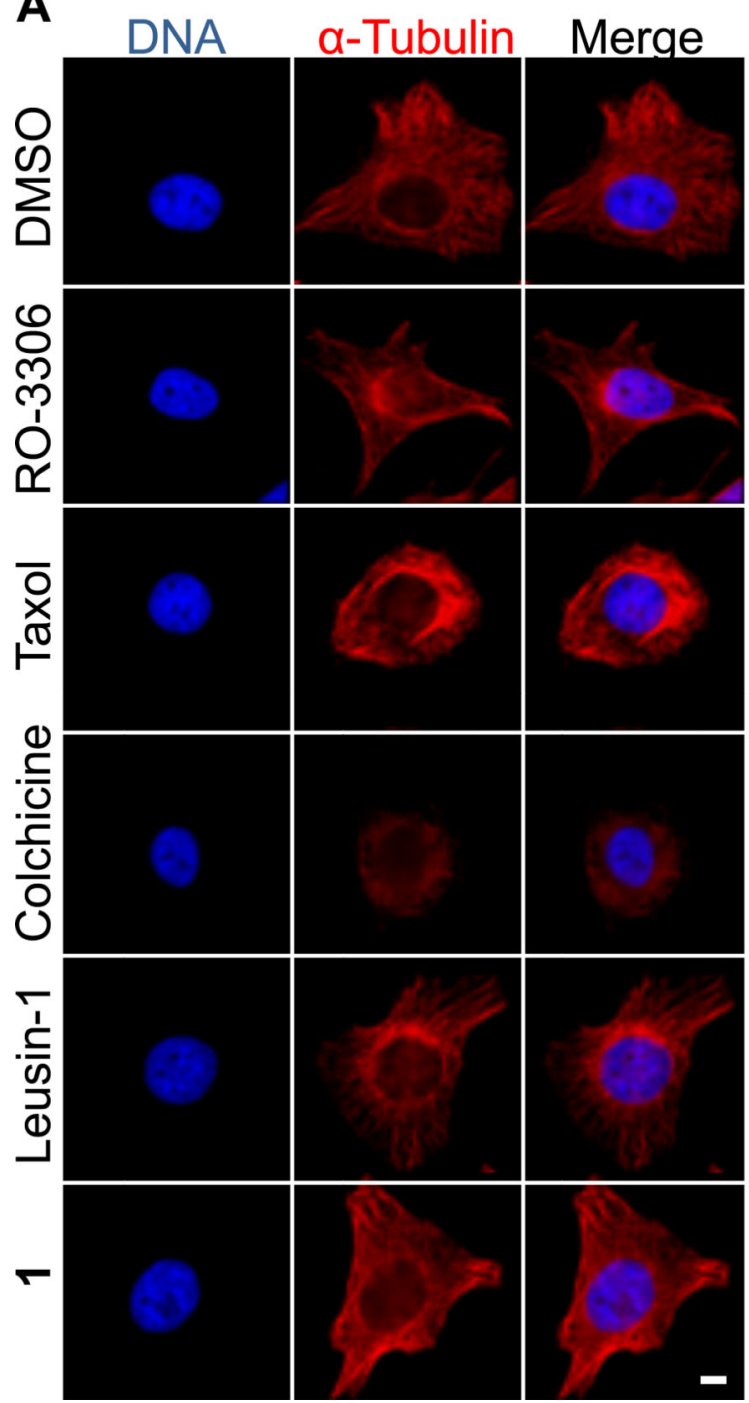

B

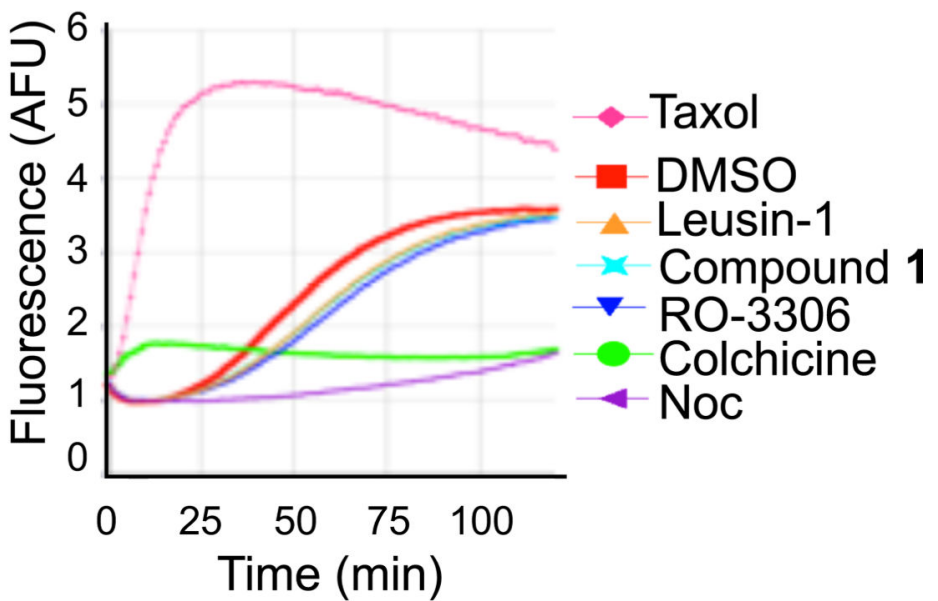

C

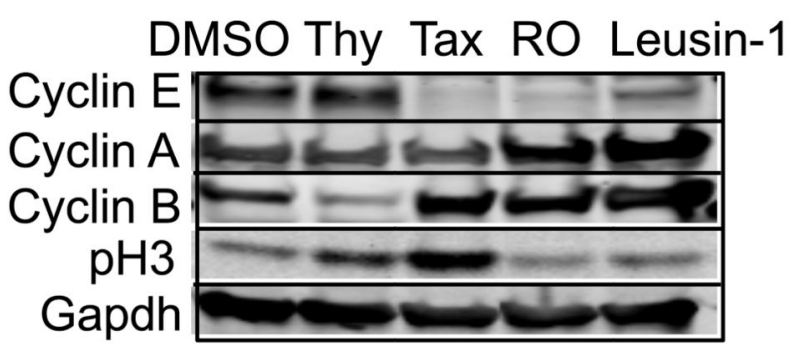

Figure 4.

Leusin-1 and compound 1 do not target tubulin. (A) Immunofluorescence microscopy of HeLa cells treated with DMSO, Leusin-1 (137 $\mu \mathrm{M})$, compound 1 (180 $\mu \mathrm{M})$, Taxol (100 nM), colchicine $(366 \mathrm{nM})$ or RO-3306 $(10 \mu \mathrm{M})$ for $3 \mathrm{~h}$ and co-stained for a-tubulin (anti- $\mathrm{a}$ tubulin antibodies, red) and DNA (Hoechst 33342, blue). Scale bar indicates $10 \mu \mathrm{m}$. For a summary of phenotypic classification for all 53 G2/M-phase inhibitors see Table S3. (B) Summary of in vitro microtubule polymerization reactions in the presence of DMSO, or 3 $\mu \mathrm{M}$ of either Leusin-1, compound 1, colchicine, nocodazole, RO-3306, or Taxol. Note that Leusin-1 and compound 1 have no effect on microtubule polymerization. Time is in minutes (x-axis) and AFU denotes arbitrary fluorescence units (y-axis). (C) CCRF-CEM cells were treated with DMSO, thymidine (2 mM), Taxol (100 nM), RO-3306 (10 $\mu \mathrm{M})$ or Leusin-1 (5 $\mu \mathrm{M})$ for $24 \mathrm{~h}$. Extracts were prepared and immunoblotted for cyclin A, B and E and for the phospho histone H3 (p-H3 ser10) marker of mitotic cells. Note that Leusin-1-treated cells have low p-H3 and stabilized cyclin A and B levels, indicative of a failure to enter mitosis, 
similar to RO-3306. In contrast, Taxol-treated cells arrest in mitosis with high levels of p-H3 and cyclin A levels are lower. 
A

C

\section{CCRF-CEM}

Taxol Cisplatin Leusin-1

Caspase-3

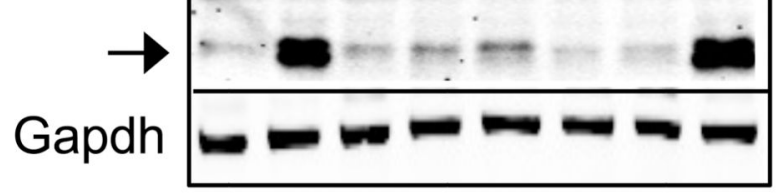

B

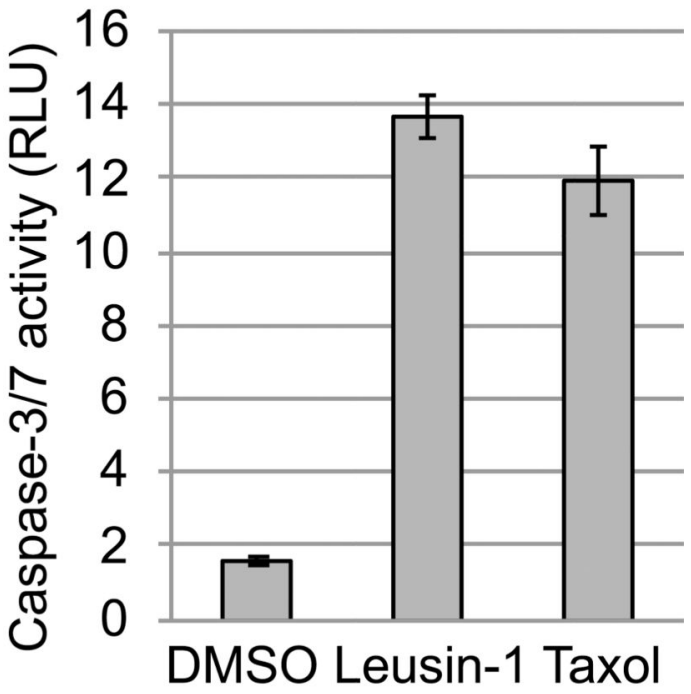

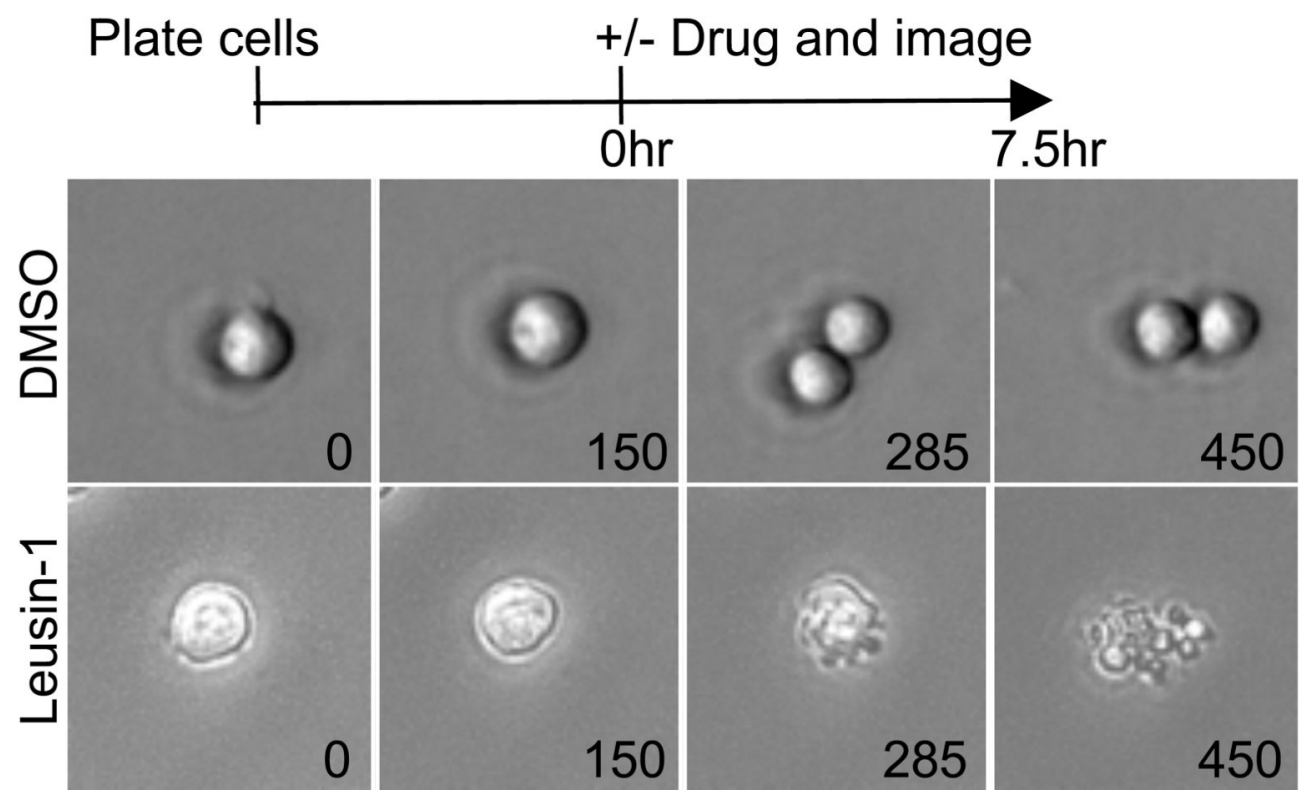

Figure 5.

Leusin-1 arrests cells in G2-phase and triggers an apoptotic cell death. (A) CCRF-CEM cells were treated with DMSO or the indicated concentrations of Leusin-1, Taxol or cisplatin for 24 h. Extracts were prepared and immunoblotted for p-H3, caspase-3 and Gapdh. Note that Leusin-1 and cisplatin-treated cells have low p-H3, indicative of a failure to enter mitosis. In contrast, Taxol-treated cells arrest in mitosis with high levels of $\mathrm{p}-\mathrm{H} 3$. Also note that Leusin-1 and Taxol treatment led to caspase-3 cleavage (cleaved product is labeled with an arrow). (B) CCRF-CEM cells were treated with DMSO, Leusin-1 (5 $\mu \mathrm{M})$, or Taxol (100 nM) for $48 \mathrm{~h}$ and the caspase-3/7 activity was quantified using the Caspase-Glo luminescent caspase activity assay. RLU indicates relative light units. Data is presented as the average \pm SDs. Note that Leusin-1 induced caspase-3/7 activation, similar to Taxol, indicative of apoptosis. (C) Live-cell time-lapse microscopy of CCRF-CEM cells treated with DMSO or Leusin-1 $(5 \mu \mathrm{M})$. Note that Leusin-1 treated cells fail to divide and undergo apoptosis. 
A

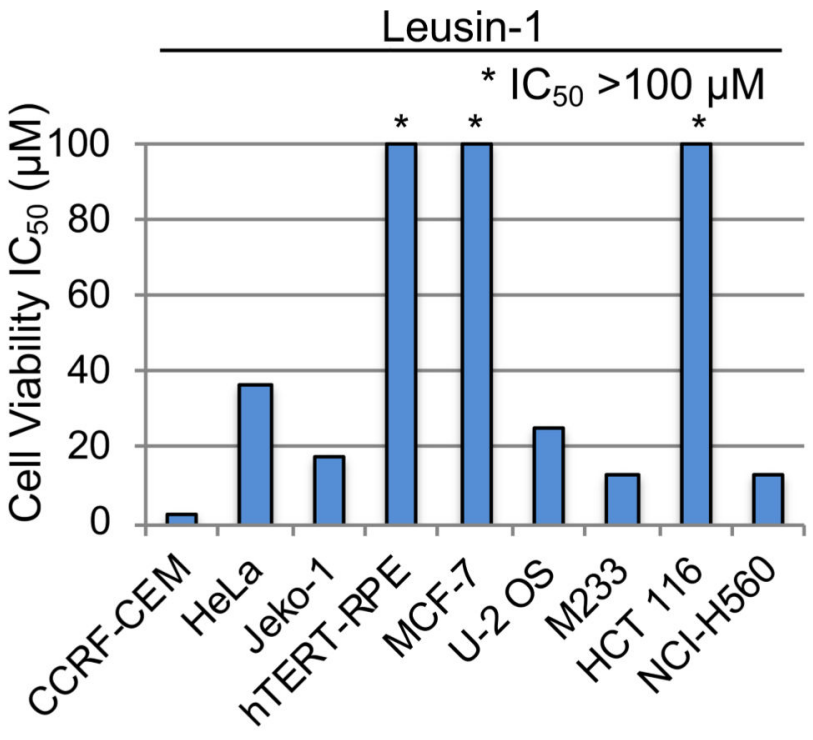

C

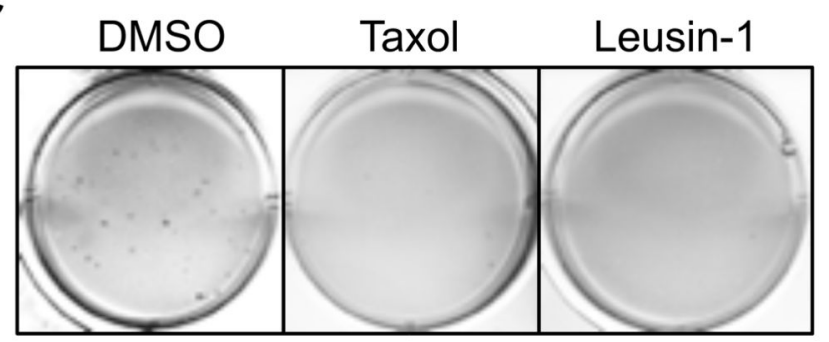

$\mathbf{E}$

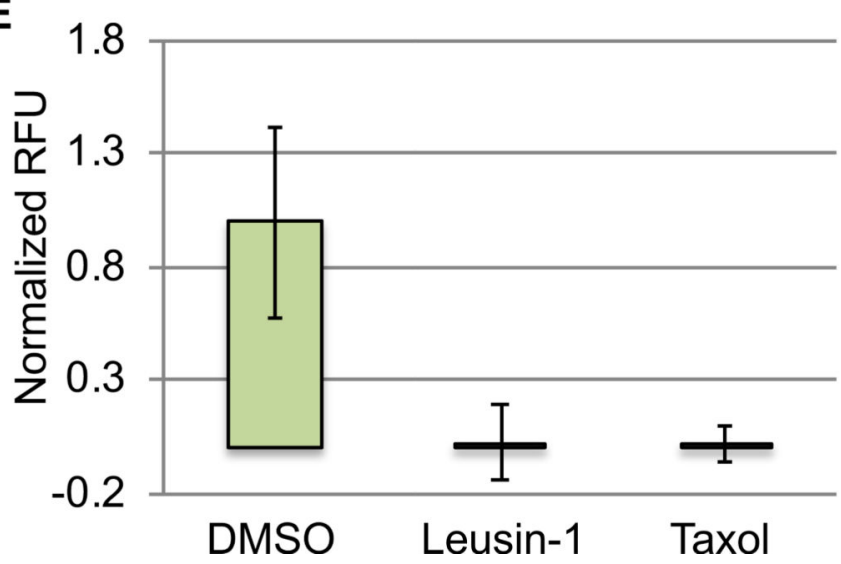

B

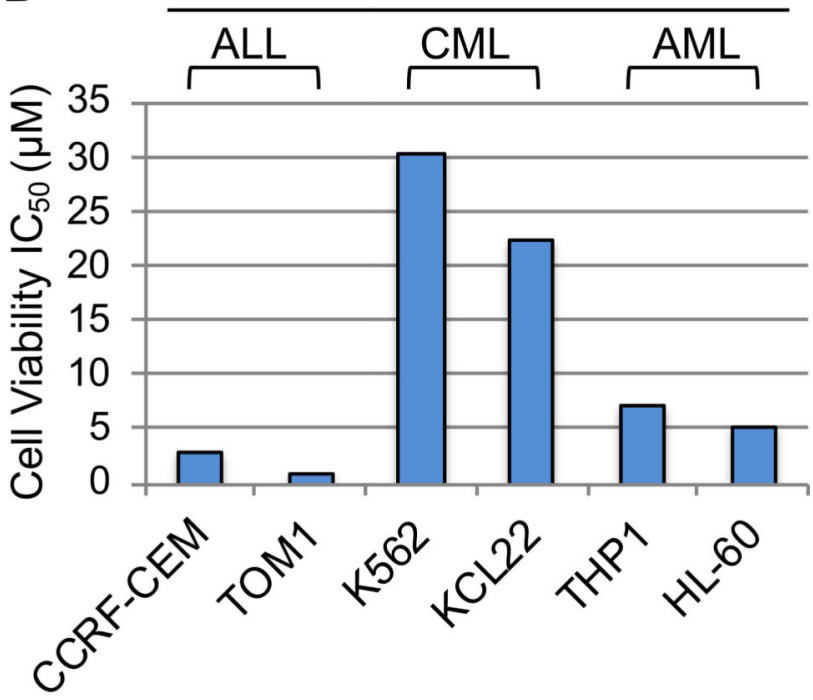

D

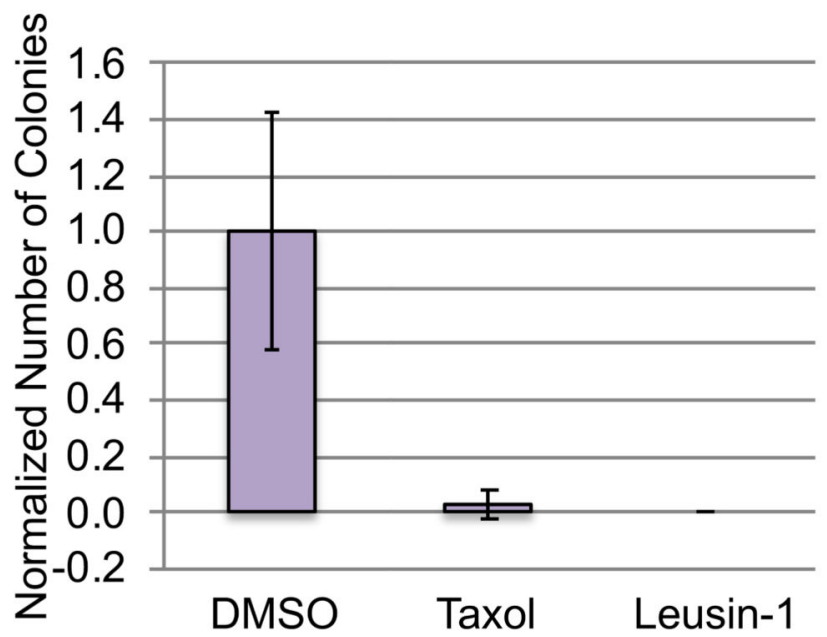

Figure 6.

Leusin-1 inhibits ALL proliferation. (A) A broad panel of cancer cell lines was treated with increasing concentrations of Leusin- 1 for $72 \mathrm{~h}$ and their cell viability $\mathrm{IC}_{50}$ was assessed using the CellTiter-Glo assay. Graph shows summary of results for cell viability $\mathrm{IC}_{50}(\mathrm{y}$ axis) for each cell line (x-axis). (B) A panel of leukemia cells were treated with increasing concentrations of Leusin- 1 and the cell viability $\mathrm{IC}_{50}$ (y-axis) was determined for each cell line (x-axis). ALL (CCRF-CEM and TOM1); AML (HL-60 and THP1); and CML (K562 and KCL22). (C-D) ALL clonogenic assay. ALL CCRF-CEM cells were treated with 
DMSO, Leusin-1 $(2 \mu \mathrm{M})$ or Taxol $(50 \mathrm{nM})$ for 3 weeks and the percent colony formation, normalized to DMSO, was quantified. Data is represented as the average percent \pm SDs. (E) ALL transformation assay. ALL CCRF-CEM cells were treated with DMSO, Leusin-1 (2 $\mu \mathrm{M})$ or Taxol $(50 \mathrm{nM})$ for 7 days and the total fluorescence was quantified. Data is represented as the average percent \pm SDs. 